\title{
Grundrechte im Näheverhältnis
}

Eine Untersuchung zur Dogmatik des Sonderstatusverhältnisses

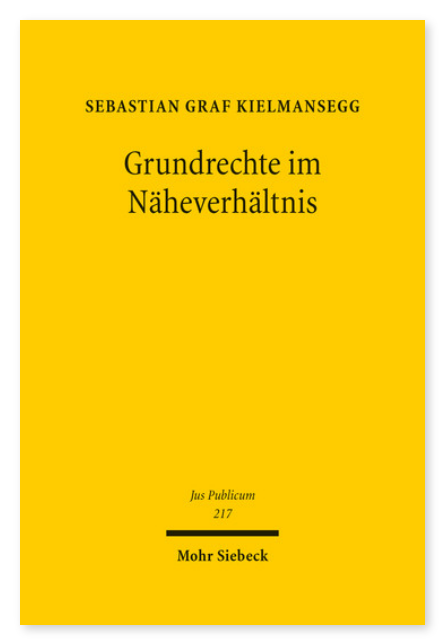

2012. XXIX, 606 Seiten. JusPubl 217

ISBN 978-3-16-152306-9

DOI 10.1628/978-3-16-152306-9

eBook PDF 159,00€

ISBN 978-3-16-152247-5

Leinen $159,00 €$
Näheverhältnisse zwischen Staat und Bürger bereiten der Grundrechtslehre seit jeher Schwierigkeiten. Als 'besondere Gewaltverhältnisse' standen sie traditionell im Kontrast zur rechtsstaatlichen Normalität des Staat-Bürger-Verhältnisses. Die Überwindung dieser Figur hat diesen Sonderstatus, so scheint es, weitgehend eingeebnet. In Wirklichkeit jedoch sind die Probleme damit eher verschleiert als gelöst. Noch immer gilt, dass die Eingliederung des Bürgers als Amtsträger oder Anstaltsnutzer mit Strukturmerkmalen einhergeht, auf die die Schablonen der allgemeinen Grundrechtsdogmatik nicht zugeschnitten sind. Noch immer gilt, dass die rechtsstaatliche Ausbalancierung individueller Freiheit und funktionaler Einbindung hier andere Schwierigkeiten aufwirft als im gewohnten Distanzverhältnis. Auf der Grundlage rechtshistorischer und rechtsvergleichender Untersuchungen unternimmt es der Autor, diese Anomalien systematisch zu erfassen und zu einem Gesamtbild der Grundrechtsdogmatik im Näheverhältnis zusammenzufügen. Diese Arbeit wurde mit dem Preis 'Sprache und Wissenschaft' der Universität Mannheim ausgezeichnet.

Sebastian Graf von Kielmansegg ist Inhaber des Lehrstuhls für Öffentliches Recht und Medizinrecht und Direktor des Instituts für Öffentliches Wirtschaftsrecht an der Christian-Albrechts-Universität zu Kiel.
Jetzt bestellen:
https://mohrsiebeck.com/buch/grundrechte-im-naeheverhaeltnis-9783161523069?no_cache=1
order@mohrsiebeck.com
Telefon: +49 (0)7071-923-17
Telefax: +49 (0)7071-51104 